\title{
Quando três gerações adoecem simultaneamente
}

Maria João Araújo, * Ana Viegas, * Ana Ribeiro**

\section{RESUMO}

Introdução: A doença pode ser causa ou consequência da rutura de uma homeostasia pré-existente na família. O médico de família ocupa um lugar privilegiado para identificar fatores de risco familiar, reconhecer recursos e estratégias aquando de doença. Esta tarefa pode tornar-se difícil quando vários membros da família adoecem em simultâneo.

Descrição do caso: A., 37 anos, sexo feminino, caucasiana, pertencente a uma família nuclear, fase IV do ciclo de Duvall. Em maio de 2012, no puerpério da segunda gravidez, inicia quadro de sudorese, astenia e perda ponderal. Em setembro apresenta febre vespertina e tosse. Recorre à Unidade de Saúde Familiar em novembro onde foram pedidos exames complementares de diagnóstico cujos resultados motivaram encaminhamento ao Serviço de Hematologia do Hospital... Em dezembro foi confirmado diagnóstico de linfoma não Hodgkin. Esteve internada para vários ciclos de quimioterapia, tendo as filhas ficado ao cuidado do marido. Este assumiu as tarefas e a responsabilidade parental para que as filhas sentissem o menos possível a ausência da mãe.

Nesse mês foi também diagnosticada neoplasia maligna do cólon à mãe de A., submetida a tratamento cirúrgico no Hospital... Em fevereiro de 2013, a filha mais velha de A. foi submetida a cirurgia otorrinolaringológica e a de 9 meses, em consulta de saúde infantil, apresentava dificuldade na posição de sentar.

Em junho, A. terminou a quimioterapia e a filha de 13 meses mantinha atraso do desenvolvimento psicomotor. Comentário: A equipa de saúde, com o objetivo de manter a funcionalidade e minimizar o impacto das várias doenças na família, procurou mobilizar e gerir os recursos de saúde e capacitar os vários membros da família no desenvolvimento de novas competências.

Palavras-chave: Família; Doença; Médicos de Família.

\section{INTRODUÇÃO}

A família é definida como um conjunto de pessoas unidas por laços de parentesco ou afinidade que coabitam e se apoiam reciprocamente. ${ }^{1}$ De acordo com a Organização Mundial de Saúde (OMS), a família é o primeiro agente social envolvido na promoção da saúde e bem-estar ${ }^{2}$ e o contexto social mais importante nos cuidados de saúde individuais. ${ }^{3}$

A doença pode ser causa ou consequência da rutura de uma homeostasia pré-existente. ${ }^{1}$

Segundo o modelo idealizado por Doherty e Campbell, ${ }^{4} \mathrm{o}$ sistema familiar encontra-se em interação cons-

*Médica interna de Medicina Geral e Familiar, USF Conde de Oeiras, ACES Lisboa Ocidental e Oeiras

*Médica interna de Medicina Geral e Familiar, USF Conde de Oeiras, ACES Lisboa Ocidental e Oeiras

**Médica Assistente Graduada de Medicina Geral e Familiar, USF Conde de Oeiras, ACES Lisboa Ocidental e Oeiras tante com o sistema de saúde e o médico de família (MF). Este último, através da sua ação multifacetada, pode intervir em todas as etapas do espectro saúdedoença: promoção da saúde e prevenção da doença, vulnerabilidade e início da doença, significado familiar do adoecer, resposta familiar à fase aguda e adaptação à doença e reabilitação.

Assim, a abordagem individual centrada na família constitui uma das ferramentas mais importantes em medicina geral e familiar (MGF) e o MF deve não só compreender os aspetos físicos da doença, mas também o indivíduo e o significado que ele e a sua família atribuem ao adoecer. ${ }^{3}$

Esta abordagem familiar permite ao MF concretizar planos terapêuticos mais efetivos na ajuda aos pacientes e às suas famílias. O trabalho conjunto com a restante equipa de saúde torna possível uma utilização mais eficiente dos recursos disponíveis. 
A gestão de cuidados de saúde é uma das atividades mais exigentes em MGF e pode tornar-se especialmente difícil quando vários membros da família adoecem simultaneamente.

\section{DESCRIÇÃO DO CASO}

\section{Apresentação da família}

A., 37 anos, sexo feminino, raça caucasiana, natural e residente em Oeiras, $12 .^{\circ}$ ano de escolaridade, atualmente desempregada. Como problemas ativos apresenta uma obesidade diagnosticada em 2007. Na lista de problemas passivos há apenas a referir um quadro de paniculite (inicialmente interpretado como eritema nodoso), arrastado e recorrente durante os anos de 2009 e 2010, vigiado em consulta de medicina interna.

Sem hábitos toxicofílicos ou medicamentosos conhecidos.

Sem história de alergias alimentares ou medicamentosas.

A. é casada, pertence a uma família nuclear na fase IV do ciclo de Duvall, com um Graffar Familiar de classe social grau 3. O agregado familiar é constituído pela utente, o marido de 39 anos, saudável, profissionalmente ati- vo (contabilista) e duas filhas do sexo feminino, uma de 6 anos de idade, a frequentar o $1 .^{\circ}$ ano de escolaridade e outra com 1 ano, integrada no jardim de infância.

A. é o $6 .^{\circ}$ elemento da fratria, com 3 irmãos do sexo masculino e 2 do sexo feminino, tendo o irmão mais velho falecido por afogamento antes do nascimento da utente. $\mathrm{Na}$ figura 1 apresenta-se o respetivo genograma. (Figura 1).

A Psicofigura de Mitchell revela uma relação próxima com os pais, sendo A. a principal cuidadora destes. Esta relação é fortalecida pelas visitas quase diárias a casa dos pais, geograficamente próxima da escola das filhas.

A. apresenta uma relação ambivalente com o marido, que se intui das queixas apresentadas de falta de atenção e apoio às filhas, motivada pelo elevado volume de trabalho a que este está sujeito, mas essencial para o sustento do agregado familiar.

\section{Linha de Medalie}

Em maio de 2012, A. recorre à USF para consulta de revisão do puerpério da segunda gravidez. A equipa de saúde pretendeu explorar o cumprimento de novas tarefas e possíveis dificuldades sentidas com a chegada do novo membro da família. A. manifestou alguma di-

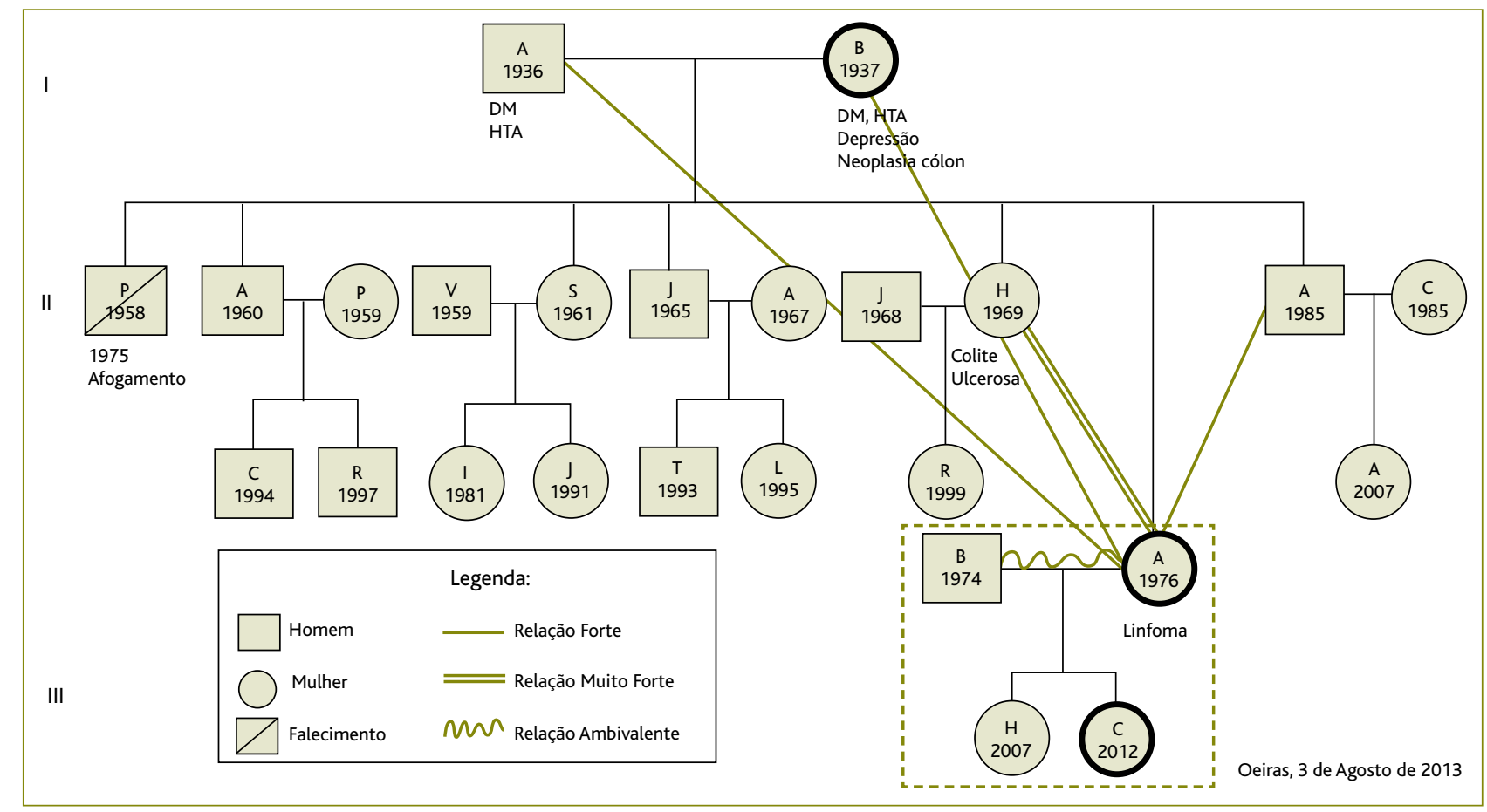

Figura 1. Genograma familiar e psicofigura de Mitchell. 
ficuldade na gestão da quase totalidade das tarefas familiares que atribuía à falta de apoio do marido. Nesta consulta, A. refere cansaço geral desde o início do puerpério, com cerca de 2 meses de evolução e apresenta palidez cutânea e perda ponderal. Os resultados analíti$\cos$ do $3 .^{\circ}$ trimestre da gravidez não tinham evidenciado qualquer alteração relevante para este período, sendo o valor de hemoglobina de 11,3 g/dl. A. Apresentava, nesta consulta, uma perda ponderal de cerca de $10 \mathrm{Kg}$ desde o final da gravidez, correspondendo a menos 5,5 Kg do que o seu peso habitual pré gravidez.

Foi realizada citologia, dada indicação para iniciar anticoncetivo oral progestativo (uma vez que se encontrava a amamentar) e pedida avaliação analítica de acordo com as queixas apresentadas [hemograma completo, glicemia em jejum, hormona estimulante da tiróide, velocidade de sedimentação (VS) e proteína C reativa (PCR)]. A realização destas análises foi protelada por A. durante meses.

A. trazia a filha mais nova às consultas de vigilância de saúde infantil e juvenil (SIJ), de acordo com a periodicidade estabelecida.

Em agosto de 2012 recorre a uma consulta de "Doença Aguda" da unidade com queixas de cansaço mantido, sudorese para pequenos esforços e tosse escassa de aparecimento há uma semana. Uma vez que não tinha realizado a avaliação analítica solicitada, reforçou-se a importância de fazer os exames pedidos, acrescentando-se uma radiografia do tórax à avaliação clínica.

Além da avaliação das queixas físicas, a equipa procurou perceber qual a situação da relação com o marido e criou oportunidade para abordar cuidados antecipatórios essenciais à fase de transição do ciclo de vida que se aproximava - entrada da filha mais velha para a escola primária.

Em novembro de 2012, na sequência da consulta de vigilância de SIJ da filha mais nova, e por insistência da equipa de família, é agendada para A. uma consulta no próprio dia por agravamento do quadro clínico. A. apresentava agora queixas de sudorese profusa em repouso e mais intensa durante o período noturno, astenia, anorexia e perda ponderal quantificada de $4,5 \mathrm{Kg}$ nos últimos 6 meses. Relatava ainda lesões da mucosa oral, gengivorragias, tosse produtiva e febre vespertina com 2 meses de evolução. Foi solicitado à utente a realização de ECD dirigidos (hemograma completo, ferro, fer- ritina, transferrina, glicemia em jejum, VS, PCR, aspartato transferase, alanina aminotransferase, fosfatase alcalina, gama GT, beta 2-microglobulina, creatinina, proteinograma, pesquisa de sangue oculto nas fezes, urina II, eletrocardiograma, tomografia computadorizada (TC) toraco-abdomino-pélvica). A. ainda não tinha apresentado nenhum dos ECD pedidos anteriormente, alegando falta de tempo.

Pela urgência em mostrar os resultados dos ECD, recorre à USF 5 dias mais tarde tendo sido atendida numa “Consulta de Intersubstituição". A TC revelava doença linfoproliferativa com hepatoesplenomegalia e múltiplos elementos ganglionares aumentados desde as regiões axilares até às regiões inguinais com predomínio abdominal superior. Os resultados dos ECD motivaram contacto imediato com a MF e consequente contacto telefónico e encaminhamento urgente ao Serviço de Hematologia do Hospital...

Em dezembro de 2012 foi confirmado o diagnóstico de linfoma não Hodgkin difuso de grandes células, em estádio IVb.

Desde então, A. esteve internada para vários ciclos de quimioterapia (QT), tendo as filhas ficado ao cuidado do marido. Este abraçou as tarefas solicitadas e assumiu a responsabilidade parental para que as filhas sentissem o menos possível a ausência da mãe. Nesta fase, a equipa de saúde procurou tornar-se mais disponível aos diferentes membros da família.

Ainda em dezembro de 2012, a mãe de A., de 76 anos de idade, mostra o resultado de colonoscopia total, realizada na sequência de pesquisa de sangue oculto nas fezes positiva. O estudo apresentava neoformação estenosante a $20 \mathrm{~cm}$ da margem do ânus, com histologia compatível com adenocarcinoma moderadamente diferenciado T4N0M0. Este novo diagnóstico foi alvo de referenciação urgente ao Serviço de Cirurgia do Hospital... A referenciação intencional a este hospital iria permitir as visitas mãe-filha durante o internamento de ambas. A mãe de A. foi submetida a sigmoidectomia entre o $2 .^{\circ}$ e o $3 .{ }^{\circ}$ ciclo de QT da filha.

Sendo A. a principal cuidadora dos pais e estando mãe e filha doentes, o conhecimento privilegiado da família alargada e da dinâmica familiar permitiu ao MF recrutar outros membros (irmãos de A.) para cuidar da mãe, o que veio a fortificar relações e laços familiares.

Em fevereiro de 2013, a filha de 6 anos foi submeti- 
da a cirurgia otorrinolaringológica eletiva - adenoidectomia e miringotomia. No dia seguinte à alta da filha, A. é internada para o $4 .^{\circ}$ ciclo de QT.

Durante o mesmo mês, a filha mais nova de A., na consulta de vigilância de SIJ dos 9 meses, apresenta dificuldade na posição de sentar e diminuição da força dos membros inferiores. Foi solicitada maior estimulação motora e mantida vigilância da situação por parte da equipa de família.

Passado um mês, e depois de estimulação intensa por parte dos pais, das educadoras de infância e da enfermeira da saúde escolar da Unidade de Cuidado na Comunidade, a reavaliação denota alguma melhoria do equilíbrio do tronco na posição de sentada.

Em junho de 2013, A. terminou os ciclos de QT e traz a filha mais nova, com 13 meses, à consulta que, apesar de alguma evolução favorável, mantém atraso do desenvolvimento motor e da linguagem.

A equipa de saúde manteve a flexibilidade do horário de atendimento de acordo com a disponibilidade dos pais. Foram também realizadas consultas de SIJ extra-plano à filha mais nova, não só com o intuito de reavaliação e seguimento das alterações encontradas, mas também como fonte de apoio do sistema familiar.

A. sofre novo internamento em agosto de 2013 por doença refratária primária, em progressão após oito ciclos de QT. É proposta uma segunda linha de tratamento, com transplante alogénico de progenitores hematopoéticas de eventual irmão dador compatível.

Em setembro de 2013, a filha mais nova de A., com 16 meses, volta à consulta de SIJ, altura em que apresenta hiperlaxidão articular dos membros inferiores que, em repouso, estão tendencialmente em abdução, deslocando-se arrastando a região glútea, motivo pelo qual foi referenciada à consulta de ortopedia infantil do Hospital Dona Estefânia (HDE).

Em dezembro de 2013, A. recorre à consulta de "Doença Aguda" por dor epigástrica ocasional e dificuldade em adormecer. A. reconhece o apoio que o marido prestou às filhas aquando dos seus inúmeros internamentos. No mesmo mês, A. apresenta episódio de colecistite aguda, sendo submetida a colangiopancreatografía retrógrada endoscópica.

Atualmente, A. está internada para realização de transplante alogénico.

A filha mais nova foi observada em consulta de or- topedia do HDE e encaminhada à consulta de medicina física da reabilitação para estimulação motora.

A mãe de A. encontra-se assintomática e clinicamente estável.

A figura 2 representa a evolução cronológica dos acontecimentos de vida da família de A. e a classificação das intervenções da microequipa em cada uma das fases (Figura 2).

\section{COMENTÁRIOS}

Doença: Pessoa, Família e Médico de Família

O relato de caso acima descrito é exemplo do caminhar passo a passo por todas as etapas do ciclo de saúde e doença na família, proposto por Doherty e Campbell. ${ }^{4}$

O MF tem a oportunidade de intervir em todo o espectro da saúde e doença e a sua abordagem influencia o viver da doença, o indivíduo e a família.

De seguida, descreve-se o percurso da família estudada no ciclo de saúde e doença e o papel desempenhado pela equipa de saúde em cada uma das etapas.

\section{Promoção da saúde e prevenção da doença}

A consulta de revisão do puerpério de A. e as várias consultas de SIJ da filha mais nova realizadas ao longo da história são oportunidades de promoção da saúde e prevenção da doença. A equipa de saúde dá a conhecer estilos de vida saudáveis e propõe-se influenciar comportamentos que determinem melhores níveis de saúde, bem-estar e redução de riscos.

\section{Vulnerabilidade e início da doença}

O início da doença de A. surge na transição da fase III para a fase IV do ciclo de vida de Duvall, transição esta que, por si só, confere maior vulnerabilidade à doença e coincide temporalmente não só com a entrada da filha mais velha para a escola, mas também com a chegada da filha mais nova e a adaptação do agregado familiar ao novo membro da família.

As tarefas de desenvolvimento educacional, de sociabilização com outras famílias no mesmo estádio de crescimento, de aceitação de um novo membro no sistema conjugal e de ajuste a novas rotinas foram comprometidas e condicionaram atraso no espectável movimento centrífugo da família.

O desemprego de um dos elementos do casal acarretou ainda dependência económica e, consequentemen- 


\begin{tabular}{|c|c|c|c|c|c|}
\hline Vida da Família & & \multicolumn{4}{|c|}{ Intervenção na Família } \\
\hline A.: Revisão do puerpério. & Maio 2012 & \multicolumn{4}{|c|}{$\begin{array}{l}\text { Educação para a saúde. } \\
\text { Cuidados antecipatórios: } \\
\text { - Adaptação ao novo membro da } \\
\text { família. } \\
\text { - Organização e distribuição de } \\
\text { tarefas familiares. }\end{array}$} \\
\hline A.: Sinais e sintomas inespecíficos. & Agosto 2012 & \multicolumn{4}{|c|}{$\begin{array}{l}\text { Cuidados antecipatórios: } \\
\text { - Transição de fase do ciclo de vida. } \\
\text { Sistema conjugal. }\end{array}$} \\
\hline A.: Doença linfoproliferativa. & Novembro 2012 & \multicolumn{4}{|c|}{$\begin{array}{l}\text { Explorar o significado de adoecer. } \\
\text { Explorar razões para procura tardia } \\
\text { de cuidados/desvalorização de } \\
\text { sinais e sintomas. }\end{array}$} \\
\hline $\begin{array}{l}\text { Mãe de A.: Carcinoma do cólon. } \\
\text { Filha mais nova de A.: Alterações } \\
\text { do desenvolvimento motor. }\end{array}$ & Dezembro 2012 & \multirow{6}{*}{ 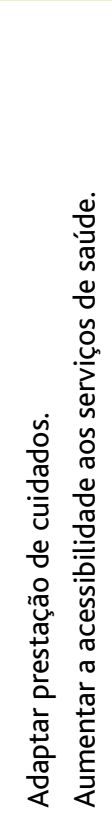 } & \multirow{6}{*}{ 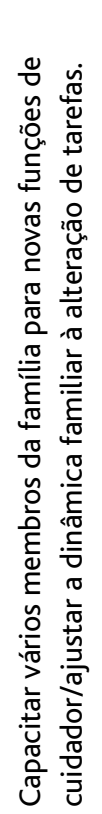 } & \multirow{6}{*}{ 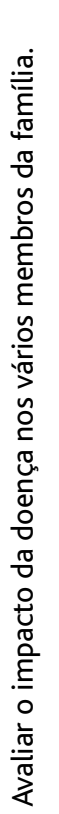 } & \multirow{6}{*}{ 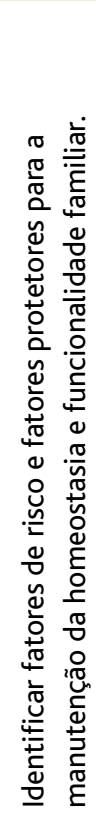 } \\
\hline $\begin{array}{l}\text { A.: Internamentos e tratamentos } \\
\text { de QT. }\end{array}$ & Fevereiro 2013 & & & & \\
\hline $\begin{array}{l}\text { Filha mais nova de A.: Atraso do } \\
\text { desenvolvimento psicomotor. }\end{array}$ & Junho 2013 & & & & \\
\hline $\begin{array}{l}\text { A.: Novos tratamentos de QT por } \\
\text { doença refratária. }\end{array}$ & Agosto 2013 & & & & \\
\hline $\begin{array}{l}\text { Filha mais nova de A.: } \\
\text { Referenciação à consulta de } \\
\text { ortopedia infantil. }\end{array}$ & Setembro 2013 & & & & \\
\hline A.: Colecistite aguda. & Dezembro 2013 & & & & \\
\hline Vida da Família & & \multicolumn{4}{|c|}{ Intervenção na Família } \\
\hline
\end{tabular}

Figura 2. Linha temporal dos acontecimentos de vida na família e classificação das intervenões da microequipa.

te, desequilíbrios financeiros e das tarefas domésticas, de que resultou a relação conjugal ambivalente descrita por A. O marido encontrava-se muito ocupado profissionalmente para fazer cumprir as suas obrigações financeiras, mas não ajudava nas tarefas domésticas e colaborava pouco nas tarefas educacionais das filhas.

A família é uma fonte de stress ou de suporte e apresenta uma influência significativa sobre a saúde.
Holmes e Rahe descrevem o impacto dos acontecimentos de vida na saúde e a sua relação com o surgir de diversas doenças, ${ }^{5}$ nomeadamente $o$ stress familiar que pode predispor à doença.

Durante este período, a microequipa de saúde, com base no conhecimento prévio que tinha desta família, identificou e avaliou os fatores protetores e de risco familiares.

Do sistema familiar em estudo destacam-se, como fatores protetores, a coesão e a organização familiar. De acordo com o modelo de Olson, podemos individualizar e caracterizar as três dimensões.

Ao estudar a família alargada, segundo o modelo de Olson, ${ }^{6}$ verifica-se uma elevada coesão demonstrada pela forte ligação emocional entre os vários elementos. Contudo, percebe-se que possa existir alguma perda reativa de autonomia individual. A adaptabilidade foi manifestada pela capacidade de mudança do sistema familiar perante uma situação de doença e de stress, com o assumir de novos papéis e com a alteração de algumas regras relacionais. Esta alteração foi especialmente evidente no cônjuge de A., que assumiu maior responsabilidade parental e se tornou disponível para A. e para as filhas.

Aquando do diagnóstico da neoplasia da mãe de A., também se verificou um recrutamento de outros irmãos para partilhar as responsabilidades do cuidado aos pais.

A comunicação entre todos os membros da família foi facilitadora do processo de mudança. 
À luz deste modelo, um sistema familiar saudável e funcional consegue oscilar em equilíbrio, mudar e voltar a reorganizar a sua estrutura durante o tempo necessário para resolução da fase de transição que atravessa. ${ }^{6}$

Como fatores de risco nesta família destacam-se a dificuldade do casal em lidar com a desigualdade de participação nas tarefas financeiras e domésticas e o adoecer simultaneamente de vários membros da família. A importância dos papéis que cada um dos diferentes membros doentes desempenha no seio familiar, a gravidade individual de cada uma das doenças e a intensidade da sintomatologia acompanhante refletem-se na perda de qualidade de vida e consequente disrupção das tarefas familiares.

\section{Avaliação da doença}

A avaliação da doença engloba a exploração do significado do adoecer e da doença nas expectativas, crenças e medos não só do indivíduo mas também da sua família.

A procura oportunística de cuidados de saúde, a demora na realização dos ECD solicitados e a desvalorização dos sinais e sintomas apresentados por A. foi várias vezes questionada pela equipa de saúde.

O MF deve ter em conta que a procura e a utilização dos serviços são influenciadas por fatores individuais mas também familiares e económicos.

Os contactos de A. com a equipa de família existem desde o início da sua vida de casal, antes do nascimento da filha mais velha, mas estabelecem-se durante o período relatado pela procura indireta e oportunística de cuidados e a evolução do quadro clínico é percecionada através das consultas de vigilância de SIJ da filha mais nova.

Por insistência médica foi agendada uma consulta para a própria.

A atitude de A. perante a sua sintomatologia pode não só representar um processo de negação da doença como também evidenciar dificuldade na gestão do tempo e das tarefas diárias, já que A. era a cuidadora principal das duas filhas e dos pais.

Há que ter em conta que muitas famílias apresentam um elemento perito em assuntos relacionados com a saúde dos seus elementos, o expert em saúde. ${ }^{3}$ Toda a família, e em especial este membro, vai influenciar o conhecimento, os mitos, as crenças do indivíduo e contribuir para a decisão de procura ou não da equipa de saúde.

Da avaliação realizada pareceu-nos que A. apresentava este papel de expert em saúde na família, já que era a principal cuidadora dos pais. Quando esse mesmo elemento adoece é maior o impacto da doença no indivíduo e na família, pelo que a doença de A. teve impacto significativo na família nuclear e alargada.

\section{Resposta à fase aguda}

Uma vezinstalada a doença é importante acompanhar a resposta do indivíduo e da família à sua fase aguda.

A escala de Readaptação Social de Holmes e Rahe destaca o surgir de doença grave na família como uma situação de crise com importante índice de probabilidade de desenvolver doença e um dos desafios mais difíceis a que a família pode estar sujeita. ${ }^{5}$

Neste caso clínico, na fase aguda de doença, conseguiu-se mobilizar a família nuclear e alargada em busca de recursos para dar suporte aos vários membros doentes.

Os irmãos de A. encarregaram-se dos cuidados prestados aos pais, em especial à mãe, com diagnóstico recente de neoplasia do cólon.

A comunicação entre os vários membros da família permitiu agilizar meios e otimizar estratégias de apoio.

Após o conhecimento da doença, a microequipa desenvolveu esforços no sentido de melhorar a acessibilidade aos serviços de saúde e de capacitar os vários membros, em especial o marido de A., para novas tarefas e responsabilidades adquiridas.

Vários estudos demonstram que o stress dos cuidadores pode ser superior ao do membro doente e que um dos fatores que contribui para este stress é a falta de informação. ${ }^{3}$ Assim, toda a equipa procurou estar mais disponível para esclarecer as dúvidas que foram surgindo.

Ao cônjuge de A. foi possível esclarecer não só dúvidas relacionadas com a doença da esposa, mas também dúvidas relacionadas com o cuidar das filhas e com as suas novas responsabilidades.

\section{Adaptação à doença}

A família é a maior fonte de apoio emocional e de suporte social e é considerada fundamental no binómio stress-saúde. O apoio da família prestado na doença abre enormes possibilidades ao MF de conseguir uma abordagem abrangente, quer individual quer familiar. 
Uma família que providencia suporte é um recurso importante no delinear de estratégias de coping para lidar com o problema e na gestão e organização dos recursos existentes.

O desempenho deste papel primordial só é possível com base numa relação médico-doente duradoura, segura e de confiança.

$\mathrm{O} \mathrm{MF}$ e a restante equipa procuraram capacitar e envolver os diferentes elementos da família para a adaptação à doença e ajuda à recuperação.

A modificação imposta de padrões familiares, papéis e tarefas originou um maior envolvimento do marido de A., que adquiriu e assumiu todas as tarefas familiares e competências parentais.

Apesar do atraso de desenvolvimento da filha mais nova de A. poder ser fruto da situação de crise e das dificuldades vividas, foi necessário excluir outras etiologias.

Com a apresentação deste caso pretendeu-se enfatizar a importância do MF no delinear de estratégias para manter a funcionalidade e minimizar o impacto da doença no doente e na família. Este relato de caso é também paradigmático da forma como a família pode influenciar a interação do doente com o sistema de saú- de nas diversas fases enunciadas no ciclo de Doherty and Campbell.

\section{REFERÊNCIAS BIBLIOGRÁFICAS}

1. Rebelo L. A família em medicina geral e familiar: conceitos e práticas. Lisboa: Verlag Dashofer; 2011. ISBN 9789896421939

2. World Health Organization. Statistical indices of family health. 1991;589:17.

3. Ribeiro C. Família, saúde e doença: o que diz a investigação. Rev Port Clin Geral. 2007;23(3):299-306.

4. Doherty WA, Campbell TL. Families and health. Beverly Hills, CA: Sage; 1988.

5. Holmes TH, Rahe RH. The social readjustment rating scale. J Psychosom Res. 1967;11(2):213-8.

6. Olson DH. Circumplex model of marital and family system. J Fam Ther. 2000;22(2):144-67.

\section{CONFLITOS DE INTERESSE}

As autoras declaram não ter conflitos de interesse.

\section{ENDEREÇO PARA CORRESPONDÊNCIA}

Maria João Araújo

Rua do Mato da Mina, $n^{\circ}$ 34, Quinta da Beloura, 2710-692, Sintra

E-mail: mariajoaoaraujo@gmail.com

Recebido em 19-01-2014

Aceite para publicação em 22-07-2014

\section{ABSTRACT}

\section{WHEN THREE GENERATIONS FALL ILL SIMULTANEOUSLY}

Introduction: Disease may be a cause or consequence of loss of family homeostasis. The general practitioner plays a special role in identifying family risk factors and recognizing resources and coping strategies during illness. This may be difficult when several family members are ill simultaneously.

Case description: A. is a 37 year-old, Caucasian female, belonging to a nuclear family, in phase IV of the Duvall cycle. In May 2012, after the birth of her second child, she experienced sweating, weakness and weight loss. Four months later, she experienced evening fever and cough. She presented to the Family Health Unit in November and was referred for diagnostic tests. She was then referred to the Hematology Service of a local hospital. In December the diagnosis of non-Hodgkin lymphoma was made. A. was hospitalized several times for chemotherapy and her daughters remained in the care of her husband. The husband performed many required tasks and assumed all parental responsibility, minimizing the effects of the absence of the mother. In January, A.'s mother, was diagnosed with colorectal cancer and was admitted for surgery in the same hospital. Referral to the same hospital allowed visits between mother and daughter. On February, the eldest daughter aged 6 years had ENT surgery and the 9 month-old daughter had difficulty sitting. In June, A. completed her chemotherapy and the 13-month old daughter still had delayed motor and language development.

Comment: The health care team, in order to maintain family function and minimize the impact of several diseases on the family, sought to mobilize and manage existing resources and empower different family members in developing new skills.

Keywords: Family; Disease; Physicians, Family. 